\title{
Anthropometric profile and complications in patients with diabetes mellitus seen at Maluti Adventist Hospital, Lesotho
}

\author{
MT Makwero ${ }^{a}$, WF Mollentze ${ }^{b}$, G Joubertc $^{\text {iD }}$ and WJ Steinberg ${ }^{a *}$ iD \\ a Department of Family Medicine, University of the Free State, Bloemfontein, South Africa \\ ${ }^{b}$ Department of Internal Medicine, University of the Free State, Bloemfontein, South Africa \\ 'Department of Biostatistics, University of the Free State, Bloemfontein, South Africa \\ *Corresponding author, email: steinbergwj@ufs.ac.za
}

Background: Patients attending outpatient departments for follow-up of diabetes mellitus (DM) may seem content about the control of their disease. However, complications resulting from DM may present before diagnosis and treatment initiation or continue to develop while on treatment.

Aim: This study aimed to report on the prevalence of DM complications in patients with DM at Maluti Adventist Hospital, Lesotho. Methods: A cross-sectional study was conducted in 150 DM patients recruited from Maluti Adventist Hospital's newly formed clinic between May and June 2009. Demographic information was obtained through a structured interview. Patients underwent physical and eye examinations to obtain an anthropometric profile and identify DM complications. Laboratory and ECG investigations were done to establish level of glycaemic control and identify other complications.

Results: Patients were female (80.7\%) with a mean age of 58.2 years (standard deviation 13.2). Almost all patients had type 2 DM $(94.7 \%)$ and $60.1 \%$ had been diagnosed during the preceding five years. The most common co-morbidity was hypertension $(85.3 \%)$ and $49.7 \%$ of patients were obese (mean body mass index $30.4 \mathrm{~kg} / \mathrm{m}^{2}$ ). Patients had poor short-term $(46.2 \%)$ and longterm $(57.5 \%)$ glycaemic control. Nearly half $(43.3 \%)$ of the patients had evidence of peripheral neuropathy. Almost $60 \%$ of the patients had a blood pressure of $>130 / 80 \mathrm{mmHg}$. Of the 128 patients seen by the ophthalmologist, $29.9 \%$ had evidence of cataracts in both eyes. Funduscopic abnormalities were found in $32.8 \%$ of the patients. Patients with complications or poor glycaemic control had been diagnosed for a significantly longer time.

Conclusion: Patients showed evidence of DM complications at the time of study. Coupled with significant co-morbidities and high body mass index, the risk of morbidity and mortality is high. A comprehensive approach is needed in managing these patients, if meaningful reductions in morbidity and mortality are to be achieved.

Keywords: anthropometric profile, complications, diabetes mellitus, eye examination, Lesotho, physical examination

\section{Introduction}

Diabetes mellitus (DM) is a non-communicable disease, diagnosed and categorised by the consequential hyperglycaemia caused by deficiencies in insulin secretion and/or action. ${ }^{1,2}$ Type 1 DM develops due to a serious insufficiency of insulin production and secretion caused by a complex mixture of genetics and autoimmune processes. This form of the disease often develops early on in the patient's life. Type $2 \mathrm{DM}$, which includes the vast majority of patients, is frequently preceded by excessive secretion of and resistance to insulin. Although ageing, genetic predisposition and environmental factors contribute to insulin resistance and eventual $\beta$-cell failure, there are strong indications that urbanisation and lifestyle changes such as an unhealthy diet and obesity play the main role. ${ }^{1}$ Other causes of DM may also be pregnancy, toxicity, genetic disorders or diseases of the pancreas. $^{1,3}$

Complications due to DM include microvascular and macrovascular diseases. Prevalence of the category of complication differs according to the type of DM, environmental factors, high-or low-income status of the country and, seemingly, race. ${ }^{1,3,4}$ Microvascular complications are caused by injuries to the small blood vessels. These include retinopathy (retina lesions), nephropathy (kidney) and neuropathy (nervous system). Macrovascular complications present due to arterial damage, which includes all the atherosclerotic cardiovascular, cerebrovascular conditions and peripheral vascular diseases. ${ }^{1,3}$
The damage resulting in DM complications is caused by glucose process irregularities, high blood pressure, obesity, inflammation, protein handling, lipid deviations, redox imbalances and gene regulation. ${ }^{3}$

The prevalence of DM is increasing worldwide at an alarming rate. In Africa alone, it was estimated that 19.8 million people were living with DM in 2013, and a projection estimated that in 2035 there would be 41.4 million living with this metabolic disease. ${ }^{4}$ Thus, the number of people living with DM is expected to more than double in Africa over the next two decades. The number of people with DM complications would also be expected to increase and form a large health burden on available services.

Unfortunately, the negative effects of globalisation, which include urbanisation, socioeconomic and demographic transitions, inactive lifestyle, unhealthy diets and consequential obesity, put developing countries in sub-Saharan Africa under severe strain. Diagnosis and treatment often initiate late due to struggling economic and health-care systems. ${ }^{4-6}$

In Lesotho, little information on DM complications is known in the public sector. It is estimated that approximately 42000 people in this country will develop DM by 2030. In 2009, DM was the leading non-infectious cause of admissions to public hospitals in Lesotho. ${ }^{7}$ Thinyane and Theketsa ${ }^{7}$ investigated DM 
patients admitted to Queen Elizabeth II Referral Hospital in 2011. They found glycaemic control to be very poor with heightened presenting complications. These complications, combined with poor screening and self-care, led to hastened re-hospitalisation. Sorace $^{8}$ evaluated DM patients screened at Maluti Adventist Hospital between November 2010 and April 2011, and found that $70.9 \%$ developed diabetic retinopathy, with the majority being proliferative.

Maluti Adventist Hospital is a rural regional hospital in Lesotho with an estimated 30000 general outpatient consultations, 2.5$3 \%$ of which are for patients with DM, and 250 admissions are due to DM complications per year. The hospital serves the Mapoteng community council within the greater Berea District of Lesotho.

\section{Aim}

The aim of this paper is to report on the anthropometric profile and the prevalence of DM complications in patients with DM at Maluti Adventist Hospital, Lesotho in 2009.

\section{Methods}

\section{Study design and setting}

This was a cross-sectional analytical study with qualitative elements. The study was conducted at the Maluti Adventist Hospital, a rural regional hospital in Lesotho. The overall study included anthropometric measurements (height, weight and waist circumference), investigations (blood glucose levels and $\mathrm{HbA1c}$ levels), physical examination and an eye examination, and attempted to link the patients' knowledge, attitude and practices with their DM control and complications. For the purposes of this article, only the DM complications are reported on.

\section{Sample population and sampling strategy}

The study population consisted of all patients, including newly diagnosed patients, with DM presenting to Maluti Adventist Hospital. The majority of patients included in the study were recruited at the weekly Diabetes and Hypertension Chronic Care Outpatient Clinic, recently opened at this hospital. Diabetes mellitus patients admitted to the wards were also approached for inclusion. The study period was from May 2009 to June 2009. Participants had to be 18 years and older, and willing to give written consent to be included in this study. Patients who were too sick to give consent and/or to cooperate were excluded.

The sample size was 150 patients. This was based on 2000 to 3000 general consultations per month at the hospital of which 2.5\% were DM consultations. Due to financial constraints, only 137 subsequent patients had their $\mathrm{HbA1c}$ levels measured.

\section{Data collection}

Data were collected through an interview using a structured questionnaire developed for the study. Patients were approached when they presented for their regular check-up visits. The patients were given an information leaflet before signing consent. The interviews were conducted by two student nurses trained to administer the questionnaire in SeSotho. Relevant demographic data collected included age, gender, level of education, type of DM and year of diagnosis. Any documented complications of DM from previous records and any other comorbid states of significance were noted.

\section{Anthropometric measurements}

Anthropometric measurements included height $(\mathrm{cm})$, weight $(\mathrm{kg})$ and waist circumference $(\mathrm{cm})$. Waist circumference of above $80 \mathrm{~cm}$ in women and above $94 \mathrm{~cm}$ in men was considered abnormal according to International Diabetic Federation (IDF) guidelines. ${ }^{9}$ Body mass index (BMI) in $\mathrm{kg} / \mathrm{m}^{2}$ was calculated from the height and weight values. A BMI of 18.5-24.9 was considered normal, $25.0-29.9$ overweight and $\geq 30$ obese. $^{10}$

\section{Investigations}

Investigations of the measures of DM control included nonfasting or fasting blood glucose levels and $\mathrm{HbA} 1 \mathrm{c}$ levels.

- Non-fasting or fasting blood glucose levels were measured (depending on whether the patient had caloric intake for eight hours prior to test) by a finger-prick test using an Optium Xceed model glucometer (Abbott Laboratories, Maidenhead, UK) by the clinic nurse to determine the patient's short-term glycaemic control. For the purpose of this study, non-fasting whole-blood glucose values $>8.0 \mathrm{mmol} / \mathrm{l}$ or fasting whole-blood glucose values $>6.0 \mathrm{mmol} / \mathrm{l}$ were regarded as poor short-term glycaemic control.

- HbA1c was measured by drawing $3 \mathrm{ml}$ of whole venous blood, which was analysed within 72 hours using the In $2 \mathrm{it}^{\oplus}$ Analyzer (Bio-Rad Laboratories, Hercules, CA, USA). For this study, values $>7.0 \%$ were indicative of poor long-term glycaemic control.

\section{Physical examinations}

The first author performed physical examinations to identify DM complications. The following DM complications were documented as either present (mild, moderate or severe) or absent: acute complications including hypoglycaemic coma and hyperglycaemia complications namely diabetic ketoacidosis (DKA) and hyperosmolar non-ketotic coma (HONK), and chronic complications including peripheral neuropathy, nephropathy and ECG evidence of relevant cardiovascular abnormalities. Systemic hypertension was noted as a co-morbid condition.

- Peripheral neuropathy was qualitatively measured using the United Kingdom (UK) peripheral neuropathy coding system and, if present, was recorded as mild, moderate or severe. ${ }^{12}$

- Nephropathy was deemed present if proteinuria $>300 \mathrm{mg}$ per day (2+) was present on an ordinary urine dipstick in the absence of an overt urinary disease. ${ }^{13}$ If the dipstick showed a negative response, a confirmatory test was done on the same sample with a Micral-Test ${ }^{\oplus}$ urine dipstick (Roch Diagnostics, Basel, Switzerland).

- A 12-lead electrocardiogram (ECG) was done to assess left ventricular hypertrophy and other relevant findings. The ECG tracings were analysed according to the Minnesota coding system. ${ }^{14}$

- Blood pressure was measured with an aneroid sphygmomanometer in a sitting position after 5 minutes' rest according to South African Hypertension Society guidelines. ${ }^{11}$ A blood pressure of $130 / 80 \mathrm{mmHg}$ or less was considered normal as recommended by the IDF. 9

\section{Eye examination}

To assess the presence of a cataract, a direct light pupillary reflex with pen touch was done. If the light reflex was absent, it was assumed the white pupil was from a cataract. The ophthalmologist at the care clinic conducted the eye examinations. Diabetic retinopathy was assessed by fundoscopy through a dilated pupil 
unless the patient had glaucoma. The presence of any diabetic retinal changes was noted. Findings such as cotton wool spots were recorded for each eye separately according to what was observed.

\section{Pilot study}

A pilot study was carried out with a sample of 10 consecutive patients who were able to give consent. No major technical or methodological problems were identified. Data from the pilot study were included in the main study.

\section{Data analysis}

Statistical analysis was done by the Department of Biostatistics, Faculty of Health Sciences of the University of the Free State (UFS), using SAS ${ }^{\circledR}$ Version 9.1 (SAS Institute, Cary, NC, USA). Results are summarised by frequencies and percentages (categorical variables) and means, standard deviations or percentiles (numerical variables, based on data distribution). Associations were assessed using relative risks (RR) with 95\% confidence intervals ( $\mathrm{Cls}$ ) and appropriate hypothesis testing. $P$ values $<0.05$ were considered significant.

\section{Ethical considerations}

The study was approved by the Ethics Committee of the Faculty of Health Sciences, UFS (ETOVS NR 29/09). Permission to conduct the study was granted by the Maluti Adventist Hospital administration.

\section{Results}

Of the 150 patients with DM included in the study, $80.7 \%$ were female (Table 1). The mean age was 58.2 years (range 19-97 years, standard deviation 13.2). Only $16.1 \%$ had tertiary-level education, with the majority (57.3\%) stating primary school as their highest level of education. The majority of patients (94.7\%) stated having been diagnosed with type 2 DM. Most patients

Table 1: Socio-demographic and disease characteristics

\begin{tabular}{|c|c|}
\hline Variable & $n(\%)$ \\
\hline \multicolumn{2}{|l|}{ Gender $(n=150)$} \\
\hline Male & $29(19.3)$ \\
\hline Female & $121(80.7)$ \\
\hline \multicolumn{2}{|l|}{ Level of education ( $n=143$ ) } \\
\hline None & $9(6.3)$ \\
\hline Primary & $82(57.3)$ \\
\hline Secondary & $29(20.3)$ \\
\hline Tertiary & $23(16.1)$ \\
\hline \multicolumn{2}{|l|}{ Type of diabetes mellitus (DM) $(n=150)$} \\
\hline Type 1 & $8(5.3)$ \\
\hline Type 2 & $142(94.7)$ \\
\hline \multicolumn{2}{|l|}{ Type of current treatment $(n=147)$} \\
\hline Oral hypoglycaemic agents (OHA) & $114(77.6)$ \\
\hline Insulin alone & $13(8.8)$ \\
\hline Insulin and $\mathrm{OHA}$ & $16(10.9)$ \\
\hline No pharmacological treatment & $4(2.7)$ \\
\hline \multicolumn{2}{|l|}{ Years since diagnosis $(n=120)$} \\
\hline $0-5$ & $72(60.1)$ \\
\hline $6-10$ & $22(18.3)$ \\
\hline $11-20$ & $19(15.8)$ \\
\hline $21-30$ & $7(5.8)$ \\
\hline
\end{tabular}

(60.1\%) were diagnosed in the past 5 years, with $21.7 \%$ being diagnosed more than 10 years ago. A large percentage (85.3\%) of the patients reported hypertension as a co-morbid condition, while $5.3 \%$ reported being HIV-positive.

A review of the patients' health passports showed that $58.7 \%$ ( $n=88$ ) had documented DM complications. For the remaining $41.3 \%$ of patients, documentation was unavailable for review or there was none written. Fifty-one patients had evidence of eye problems of whom three patients were already blind. Six patients had documented diabetic foot pathologies and one patient had undergone an amputation. There were five patients with documented diabetic nephropathy, 20 patients with diabetic neuropathy, two patients with DKA, six patients with HONK, eight patients with hypoglycaemic coma and three patients with impotence.

\section{Anthropometric measurements}

The mean weight was $75.0 \mathrm{~kg}$ (range 37-124 kg) and the mean height was $157.5 \mathrm{~cm}$ (range 140-175 cm). The mean waist circumference was $101.0 \mathrm{~cm}$ and only $14.8 \%$ of patients had the recommended waist circumference appropriate for their gender. The mean BMI was $30.4 \mathrm{~kg} / \mathrm{m}^{2}$ and $49.7 \%$ of the patients were obese. Only $17.7 \%$ had a normal BMI and $3.4 \%$ were underweight.

\section{Investigations}

Nearly half (46.2\%) had evidence of poor short-term glycaemic control according to fasting or non-fasting state. Over half (57.5\%) of the patients had HbA1c levels of $>7.0 \%$ (median 7.4\%) indicating poor long-term glycaemic control.

\section{Physical examinations}

Nearly half $(43.3 \%)$ of the patients had evidence of peripheral neuropathy with $6.0 \%$ having evidence of severe peripheral neuropathy. Of the patients diagnosed more than 10 years ago, $46.2 \%$ had peripheral neuropathy, compared with $40.4 \%$ of the patients diagnosed 10 or fewer years ago. Only $6.7 \%$ had evidence of proteinuria of more than $2+$ in the absence of urinary tract infection.

Using the Minnesota code ${ }^{14}$ to determine the prevalence of ECG findings/abnormalities, slightly over a quarter of the patients had arrhythmias and ST junction and ST depression registering at $28 \%$ and $29 \%$, respectively. Almost $60 \%$ of the patients (56.7\%) had a blood pressure of $>130 / 80 \mathrm{mmHg}$.

\section{Eye examinations}

Of the 128 patients seen by the ophthalmologist, $29.9 \%$ had evidence of cataracts in both eyes. The majority of patients (67.2\%) had normal funduscopic findings while $4.7 \%$ had evidence of diabetic retinopathy and $4.7 \%$ of retinal problems other than diabetic retinopathy.

InTable 2, the relationship between the various DM complications and the duration of the patients' DM is displayed. In general, patients with complications, especially high $\mathrm{HbA1c}(>7.0 \%)$, poor short-term glycaemic control, retinal eye changes, cotton wool spots and cataracts, tended to have had DM for a longer duration ( $p$-value $<0.05)$.

As shown in Table 3, the percentage of patients with complications is not uniformly higher in patients with poor short-term glycaemic control compared with the patients who had good short-term glycaemic control. No clear pattern regarding complications being more common in patients with high $\mathrm{HbA} 1 \mathrm{c}$ 
Table 2: Relationship between diabetes mellitus (DM) complications and patients' duration of DM

\begin{tabular}{|c|c|c|c|}
\hline Complication & Patients $(n)$ & $\begin{array}{c}\text { Median DM } \\
\text { duration } \\
\text { (years) }\end{array}$ & $p$-value \\
\hline \multicolumn{4}{|l|}{ Glycaemic control: } \\
\hline \multirow[t]{3}{*}{ Blood glucose } & & & 0.0379 \\
\hline & 73 & 5 & \\
\hline & 42 & 3 & \\
\hline \multirow[t]{3}{*}{$\mathrm{HbA} 1 \mathrm{c}$} & & & 0.0122 \\
\hline & 61 & 6 & \\
\hline & 47 & 3 & \\
\hline \multicolumn{4}{|l|}{ Chronic complications: } \\
\hline \multirow[t]{3}{*}{ Neuropathy } & & & 0.2355 \\
\hline & 50 & 5 & \\
\hline & 70 & 4 & \\
\hline \multirow[t]{3}{*}{ Proteinuria } & & & 0.0951 \\
\hline & 7 & 10 & \\
\hline & 102 & 4 & \\
\hline \multicolumn{4}{|l|}{ Co-morbid condition: } \\
\hline Blood pressure (mmHg) & & & 0.4171 \\
\hline $\begin{array}{c}\text { High } \\
(>130 / 80)\end{array}$ & 60 & 5 & \\
\hline $\begin{array}{c}\text { Normal } \\
(\leq 130 / 80)\end{array}$ & 60 & 4 & \\
\hline \multicolumn{4}{|l|}{ Eye complications: } \\
\hline \multirow[t]{3}{*}{ Cataracts } & & & 0.0157 \\
\hline & 29 & 5 & \\
\hline & 73 & 4 & \\
\hline Abnormal fundoscopy & & & 0.0135 \\
\hline Present & 33 & 6 & \\
\hline Absent & 71 & 3 & \\
\hline Microangiopathy & & & 0.9514 \\
\hline Present & 5 & 4 & \\
\hline Absent & 99 & 5 & \\
\hline Vitreous/retinal abnormal & & & 0.004 \\
\hline Present & 4 & 21.5 & \\
\hline Absent & 100 & 4 & \\
\hline Cotton wool spots & & & 0.058 \\
\hline Present & 6 & 9.5 & \\
\hline Absent & 98 & 4 & \\
\hline Macular abnormality & & & 0.2372 \\
\hline Present & 5 & 7 & \\
\hline Absent & 99 & 4 & \\
\hline
\end{tabular}

Note: *Fasting > $6.0 \mathrm{mmol} / \mathrm{l}$; non-fasting $>8.0 \mathrm{mmol} / \mathrm{l}$.

levels compared with those who had normal $\mathrm{HbA} 1 \mathrm{c}$ levels could be found.

\section{Discussion}

Overall, a considerable percentage of the patients had poor shortand long-term glycaemic control (46.2\% and $57.5 \%$, respectively). Hyperglycaemia, especially chronic, is associated with development of complications through its metabolic changes. This explains why
Table 3: Relationship between short-term and long-term glycaemic control and diabetes mellitus (DM) complications

\begin{tabular}{|c|c|c|c|c|}
\hline \multirow{3}{*}{ Complication } & \multicolumn{4}{|c|}{ Glycaemic control } \\
\hline & \multicolumn{2}{|c|}{ Blood glucose } & \multicolumn{2}{|c|}{$\mathrm{HbA1c}$} \\
\hline & $\begin{array}{c}\text { High } \\
n=97\end{array}$ & $\begin{array}{c}\text { Normal } \\
n=48\end{array}$ & $\begin{array}{c}>7.0 \% \\
n=77\end{array}$ & $\begin{array}{c}\leq 7.0 \% \\
n=57\end{array}$ \\
\hline \multicolumn{5}{|l|}{ Chronic complications: } \\
\hline \multicolumn{5}{|l|}{ Neuropathy } \\
\hline$n(\%)$ & $46(47.4)$ & $18(37.5)$ & $35(45.5)$ & $22(38.6)$ \\
\hline $\mathrm{RR}(95 \% \mathrm{Cl})$ & \multicolumn{2}{|c|}{$1.26(0.83 ; 1.93)$} & \multicolumn{2}{|c|}{$1.18(0.78 ; 1.77)$} \\
\hline$p$-value & \multicolumn{2}{|c|}{0.2575} & \multicolumn{2}{|c|}{0.4273} \\
\hline Proteinuria & $n=87$ & $n=44$ & $n=72$ & $n=50$ \\
\hline$n(\%)$ & $6(6.9)$ & $3(6.8)$ & $5(6.9)$ & $2(4.0)$ \\
\hline RR (95\% Cl) & \multicolumn{2}{|c|}{$1.01(0.27 ; 3.85)$} & \multicolumn{2}{|c|}{$1.74(0.35 ; 8.60)$} \\
\hline$p$-value & \multicolumn{2}{|c|}{1.0000} & \multicolumn{2}{|c|}{0.6990} \\
\hline
\end{tabular}

Co-morbid condition:

High blood pressure

\begin{tabular}{|c|c|c|c|c|}
\hline$n(\%)$ & $56(57.7)$ & $26(54.2)$ & $37(48.1)$ & $38(66.7)$ \\
\hline $\mathrm{RR}(95 \% \mathrm{Cl})$ & \multicolumn{2}{|c|}{$1.07(0.78 ; 1.45)$} & \multicolumn{2}{|c|}{$0.72(0.54 ; 0.97)$} \\
\hline$p$-value & \multicolumn{2}{|c|}{0.6836} & \multicolumn{2}{|c|}{0.0319} \\
\hline
\end{tabular}

Eye complications:

\begin{tabular}{|c|c|c|c|c|}
\hline Cataracts & $n=83$ & $n=41$ & $n=67$ & $n=49$ \\
\hline$n(\%)$ & $26(31.3)$ & $10(24.4)$ & $19(28.4)$ & $16(32.7)$ \\
\hline $\mathrm{RR}(95 \% \mathrm{Cl})$ & \multicolumn{2}{|c|}{$1.28(0.69 ; 2.40)$} & \multicolumn{2}{|c|}{$0.87(0.50 ; 1.51)$} \\
\hline$p$-value & \multicolumn{2}{|c|}{0.4235} & \multicolumn{2}{|c|}{0.6186} \\
\hline Abnormal fundoscopy & $n=84$ & $n=41$ & $n=69$ & $n=50$ \\
\hline$n(\%)$ & $28(33.3)$ & $14(34.2)$ & $21(30.4)$ & $17(34.0)$ \\
\hline $\mathrm{RR}(95 \% \mathrm{Cl})$ & \multicolumn{2}{|c|}{$0.98(0.58 ; 1.64)$} & \multicolumn{2}{|c|}{$0.90(0.53 ; 1.51)$} \\
\hline$p$-value & \multicolumn{2}{|c|}{0.9280} & \multicolumn{2}{|c|}{0.6805} \\
\hline Microangiopathy & $n=84$ & $n=41$ & $n=69$ & $n=50$ \\
\hline$n(\%)$ & $5(6.0)$ & $1(2.4)$ & $5(7.3)$ & $0(0)$ \\
\hline $\mathrm{RR}(95 \% \mathrm{Cl})$ & \multicolumn{2}{|c|}{$2.44(0.29 ; 20.22)$} & \multicolumn{2}{|c|}{-} \\
\hline$p$-value & \multicolumn{2}{|c|}{0.6627} & \multicolumn{2}{|c|}{0.0731} \\
\hline $\begin{array}{l}\text { Retinal/vitreous abnor- } \\
\text { mality }\end{array}$ & $n=84$ & $n=41$ & $n=69$ & $n=50$ \\
\hline$n(\%)$ & $5(6.0)$ & $1(2.4)$ & $6(8.7)$ & $0(0)$ \\
\hline $\mathrm{RR}(95 \% \mathrm{Cl})$ & \multicolumn{2}{|c|}{$2.44(0.29 ; 20.22)$} & \multicolumn{2}{|c|}{-} \\
\hline$p$-value & \multicolumn{2}{|c|}{0.6627} & \multicolumn{2}{|c|}{0.0391} \\
\hline Cotton wool spots & $n=84$ & $n=41$ & $n=69$ & $n=50$ \\
\hline$n(\%)$ & $5(6.0)$ & $3(7.3)$ & $3(4.4)$ & $5(10.0)$ \\
\hline $\mathrm{RR}(95 \% \mathrm{Cl})$ & \multicolumn{2}{|c|}{$0.81(0.20 ; 3.24)$} & \multicolumn{2}{|c|}{$0.43(0.11 ; 1.74)$} \\
\hline$p$-value & \multicolumn{2}{|c|}{0.7166} & \multicolumn{2}{|c|}{0.2780} \\
\hline Macular abnormalities & $n=84$ & $n=41$ & $n=69$ & $n=50$ \\
\hline$n(\%)$ & $5(6.0)$ & $3(7.3)$ & $4(5.8)$ & $4(8.0)$ \\
\hline $\mathrm{RR}(95 \% \mathrm{Cl})$ & \multicolumn{2}{|c|}{$0.81(0.23 ; 3.24)$} & \multicolumn{2}{|c|}{$0.72(0.19 ; 2.76)$} \\
\hline$p$-value & \multicolumn{2}{|c|}{0.7166} & \multicolumn{2}{|c|}{0.7191} \\
\hline
\end{tabular}

Notes: $\mathrm{Cl}=$ confidence interval; $\mathrm{RR}=$ relative risk.

patients with high blood glucose generally had more DM complications. As such, ways to maximise pharmacological, nutritive as well as lifestyle therapeutic interventions need to be explored and improved at each patient visit. 
The majority of participants in this study are women, which is in keeping with the usage of health facilities in rural Southern Africa. The average BMI of patients was $30.4 \mathrm{~kg} / \mathrm{m}^{2}$ with only $17.7 \%$ having a normal $\mathrm{BMI}$ and $3.4 \%$ being underweight. This does not only favour progression of DM by increasing peripheral insulin resistance and making optimal management of DM difficult, but is also an important risk factor for the development of long-term DM complications and other related diseases with the same risk factors. ${ }^{15}$

Only $14.8 \%$ of the patients had the recommended waist circumference for their gender. Coupled with other risk factors such as high BMI, high blood pressure and relative insulin resistance, the likelihood of these patients having or developing metabolic syndrome is significant, rendering systematic management of the whole syndrome crucial. ${ }^{16}$

Two-thirds of the patients already had evidence of various DM complications at the time of study. It is well known that DM induces metabolic derangements, which, with sufficient duration, render patients vulnerable to a number of DM complications. The complications may be present even at the time of DM diagnosis. ${ }^{17}$ With $21.7 \%$ of the patients having had DM for more than 10 years, it is evident that the metabolic effects of uncontrolled DM are rapidly taking a toll on their bodies with resultant morbidity and eventual mortality.

Most patients (85.3\%) had hypertension as a co-morbidity and $56.7 \%$ had a blood pressure reading of more than $130 / 80 \mathrm{mmHg}$, a value that is higher than recommended by the IDF. ${ }^{9}$ Diabetes mellitus, with its resultant metabolic derangements, induces macro/microvascular changes that tend to occur earlier and be more extensive and severe than in the non-diabetic population. Esteghamati et al. ${ }^{16}$ found DM with coexisting hypertension to be prevalent (91\%).

When looking at the duration of DM in this population, it was found that patients with complications, especially high $\mathrm{HbA} 1 \mathrm{c}$ levels, tended to have had DM for longer duration than their counterparts ( $p$-value $<0.05)$. This highlights the progressive nature of the disease, but also affirms the sad reality of endemicity of poor glycaemic control found in this population.

Only $6.7 \%$ of patients had evidence of significant proteinuria, an important independent predictor of development of macrovascular diseases and mortality. ${ }^{15,17}$ In type 2 DM, it is difficult to predict when this may become evident, especially when hypertension is also present. ${ }^{17}$ Proteinuria is especially notable in the elderly population who may have multiple risk factors for declining renal function, as this may have prognostic as well as therapeutic implications.

Neuropathy occurs early in the disease process, and may be subtle and occur in many forms. ${ }^{17}$ Peripheral neuropathy can lead to painful diabetic peripheral neuropathy and unsteadiness with resultant poor quality of life. In this sample, $43.3 \%$ had evidence of peripheral neuropathy on examination-a prevalence very similar to that reported in the Rochester study (45\%)..$^{19}$ In a study from Nigeria, Oguejiofor et al. ${ }^{20}$ found a prevalence of peripheral neuropathy of $69.2 \%$ using the UK screening test symptom score. These authors also reported that diabetic peripheral neuropathy was present in almost $100 \%$ if duration of DM exceeded 10 years. In our study, peripheral neuropathy was not as common. This may be due to the majority of patients $(78.3 \%)$ having been diagnosed with DM in the past 10 years and only $21.7 \%$ diagnosed more than 10 years ago.

A number of resting ECG changes were found in this patient population-with often more than one documented in the same patient. Of note is the prevalence of arrhythmias, ST junction and ST depression. Combined with DM and other risk factors, these ECG abnormalities are suspicious of underlying atherosclerotic cardiovascular and cerebrovascular conditions and peripheral vascular diseases. The presence of atrial fibrillation may increase the risk of thromboembolic accidents. Practitioners may well need to address this during patient visits.

In addition, Esteghamati et $a .^{16}$ found that the combination of hypertension and DM was a leading factor in interfering with or predicting more serious complications of coronary heart disease. Coupled with other cardiovascular co-morbidities, such as heart failure, and the prevalence of arrhythmias and ST abnormalities also found in this study population, the risk for adverse cardiovascular events is considerable.

Eye complications, both documented and measured, were common in this study population. A similar finding was reported by Caliskan et al., ${ }^{18}$ where the majority of DM complications identified were ocular. The Maluti Adventist Hospital does community screening and treatment of a wide range of eye problems. Patients with coexistent DM are referred to the hospital's care clinic for continued care. This may explain why ophthalmic complications may be more prevalent in this population.

\section{Study limitations}

Due to limited resources, not all patients underwent eye examinations and had an ECG or had $\mathrm{HbA} 1 \mathrm{c}$ and blood glucose levels measured. This might have affected the statistical significance of the variables measured.

\section{Conclusion}

The study showed that patients attending Maluti Adventist Hospital, Diabetes and Hypertension Chronic Care Outpatient Clinic are mainly women, on average 60 years old, with type 2 DM, co-morbid hypertension and a high BMI. Most of the patients already had pre-existing forms of DM complications. A holistic approach to the management of these patients is therefore advocated.

\section{Recommendations}

Practitioners in collaboration with patients are urged to maximise effective pharmacological, nutritive and lifestyle therapeutic interventions for better glycaemic control and resultant reduced progression of complications. This, together with continuous patient education on these matters, should strengthen efforts aimed at reducing morbidity and mortality associated with DM.

Conflict of interest - The authors declare that they have no financial or personal relationships that may have inappropriately influenced them in writing this article.

Acknowledgements - The authors are indebted to Maluti Adventist Hospital Outpatient Department staff without whose assistance data collection would have been impossible, and Ms T. Mulder, medical editor, School of Medicine, University of the Free State, and Mr J. Botes of the Department of Family Medicine, University of the Free State, for technical and editorial preparation of the manuscript. 


\section{ORCID}

G Joubert (iD http://orcid.org/0000-0002-3728-6925

WJ Steinberg (D) http://orcid.org/0000-0001-9944-1807

\section{References}

1. American Diabetes Association. Diagnosis and classification of diabetes mellitus. Diabetes Care. 2014;37(Suppl 1): S81-S90. doi:10.2337/dc14-S081.

2. Makinga PN, Beke A. A cross-sectional survey on the lifestyle and health-seeking behaviour of Basotho patients with diabetes. S Afr Fam Pract. 2013;55(2): 190-95. doi:10.1080/20786204.2013.1087433 2.

3. Forbes JM, Cooper ME. Mechanisms of diabetic complications. Physiol Rev. 2013;93(1): 137-88. doi:10.1152/physrev.00045.2011.

4. Guariguata L, Whiting DR, Hambleton I, et al. Global estimates of diabetes prevalence for 2013 and projections for 2035. Diabetes Res Clin Pract. 2014;103(2): 137-49. doi:10.1016/j.diabres.2013.11.002.

5. Hall V, Thomsen RW, Henriksen O, et al. Diabetes in Sub Saharan Africa 1999-2011: epidemiology and public health implications. A systematic review. BMC Public Health. 2011;11:564. doi:10.1186/14712458-11-564.

6. Tuei VC, Maiyoh GK, Ha CE. Type 2 diabetes mellitus and obesity in sub-Saharan Africa. Diabetes Metab Res Rev. 2010;26(6): 433-45. doi:10.1002/dmrr.1106.

7. Thinyane $\mathrm{KH}$, Theketsa $\mathrm{CE}$. Characteristics of patients admitted with diabetes in Maseru, Lesotho. Afr J Diabetes Med. 2013;21(1): 17-9.

8. Sorace Y. Prevalence of diabetic retinopathy and effect on visual acuity in a population of Lesotho. IntraMed J. 2012;1(2): 1-7. Article in Spanish

9. International Diabetes Federation (IDF). The IDF consensus worldwide definition of Metabolic Syndrome. Brussels: IDF [Internet]. 2006 [cited 2009 Jan 2]. Available from: https://www.idf.org/our-activities/ advocacy-awareness/resources-and-tools/60:idfconsensusworldwide-definitionof-the-metabolic-syndrome.html

10. Nicholas AB, Nicki RC, Brian RW, editors. Davidson's principles and practice of medicine. 20th ed. New York, NY: Churchill Livingstone Elsevier; 2006.
11. Seedat YK, Croasdale MA, Milne FJ, et al. South African hypertension guideline 2006. S Afr Med J. 2006;96(4 Pt 2): 337-62.

12. Young MJ, Boulton AJ, MacLeod AF, et al. A multicentre study of the prevalence of diabetic peripheral neuropathy in the United Kingdom hospital clinic population. Diabetologia. 1993;36(2): 150-54. doi:10.1007/BF00400697.

13. The 2012 SEMDSA guideline for the management of type 2 diabetes (Revised). JEMDSA. 2012;17(2):S1-S95. doi:10.1080/22201009.2012.1 0872287.

14. Prineas $R$, Crow $R$, Blackburn $H$. The Minnesota code manual of electrocardiographic findings. Littleton, MA: John Wright-PSG, Inc.; June 1982.

15. Scheen AJ. Current management strategies for coexisting diabetes mellitus and obesity. Drugs. 2003;63(12): 1164-84. doi:10.2165/00003495-200363120-00001.

16. Esteghamati A, Abbasi M, Nakhjavani M, et al. Prevalence of diabetes and other cardiovascular risk factors in an Iranian population with acute coronary syndrome. Cardiovasc Diabetol. 2006;5: 15. doi:10.1186/1475-2840-5-15.

17. Nathan DM. Long-term complications of diabetes mellitus. N Engl J Med. 1993;328(23): 1676-85. doi:10.1056/NEJM199306103282306.

18. Caliskan D, Ozdemir O, Ocaktan E, et al. Evaluation of awareness of diabetes mellitus and associated factors in four health center areas. Patient Educ Couns. 2006;62(1): 142-7. doi:10.1016/j.pec.2005.06.018.

19. Dyck PJ, Kratz KM, Karnes JL, et al. The prevalence by staged severity of various types of diabetic neuropathy, retinopathy, and nephropathy in a population-based cohort: the Rochester Diabetic Neuropathy Study. Neurology. 1993;43(4): 817-24. Erratum in Neurology 1993;43(11): 2345. doi:10.1212/WNL.43.4.817.

20. Oguejiofor OC, Odenigbo CU, Oguejiofor CB. Evaluation of the effect of duration of diabetes mellitus on peripheral neuropathy using the United Kingdom screening test scoring system, bio-thesiometry and aesthesiometry. Niger J Clin Pract. 2010;13(3): 240-7.

Received: 24-08-2017 Accepted: 21-12-2017 